nada serve aos residentes, nada serve para a prática oftalmológica e confunde a inteligência da população leiga no assunto.

A mensagem deve ser dirigida a todos os 54 serviços de Residência Médica coordenados pelo CBO e devemos bater firme contra o uso dessa palavra que no dicionário do Aurélio significa medida da acuidade visual e no dicionário do Houaiss significa 1- ÓPT medição do poder e da amplitude da visão (veja que confusão) por meio de optômetro (que aparelho é esse?) cf. refratometria. 2- OFT técnica ou prática profissional que pelo exame do olho, diagnostica falhas de refração e prescreve lentes e/ou exercícios apropriados (?!), sem aplicação de drogas (?!) ou tratamentos cirúrgicos. cf. oftalmologia.

Optometria é um termo importado de outros países que cometeram o erro histórico de regularizá-la como profissão. $\mathrm{O}$
Brasil já possui, em demasia, em sua história, muitos erros que penalizaram e continuam sacrificando a saúde da população. Não iremos permitir a inclusão de mais um.

Historicamente o CBO tem vencido, tenazmente, essa luta e precisa transferir aos mais jovens a conscientização do perigo que significa usarmos a palavra Optometria. Ela não nos diz nada de interessante, aliás, representa uma prática desvirtuada dos altos ideais da medicina.

Parabéns a vocês dois pelo excelente Editorial e feliz 2005.

Um grande abraço,

\section{Suel Abujamra}

Prof. Titular do Dpto. de Oftalmologia da Faculdade de Medicina Santa Amaro;

Prof. Associado do Dpto. de Oftalmologia da Faculdade de Medicina da Universidade de São Paulo.

\title{
Alguns cumprimentos aos A.B.O. pela admissão à MEDLINE
}

Ribeirão Preto, 21 de janeiro de 2005

Prof. Dr. Harley E. A. Bicas

Editor dos Arquivos Brasileiros de Oftalmologia

Em nome do Departamento de Oftalmologia, Otorrinolaringologia e Cirurgia de Cabeça e Pescoço, e no meu próprio, apresento efusivos cumprimentos, extensivos a toda a equipe de Editores Associados e colaboradores, pela indexação internacional dos Arquivos Brasileiros de Oftalmologia.

É com orgulho e alegria que vemos esse importante periódico - que desde 1938, graças aos esforços de sucessivos Editores e equipes anteriores, vem cumprindo a sua "missão" - atingir a sua "visão".

Em nome de todos os oftalmologistas do nosso Departamento agradeço por esta nova oportunidade de divulgação internacional de conhecimentos gerados em nosso meio.

Cordialmente,

Prof ${ }^{\text {a }}$ Dra. Maria de Lourdes Veronese Rodrigues Chefe do Departamento de Oftalmologia, Otorrinolaringologia e Cirurgia de Cabeça e Pescoço da Faculdade de Medicina de Ribeirão Preto - USP.

São Paulo, 3 de dezembro de 2004

Prof. Dr. Harley Bicas,

Fui informado por amigos da Universidade de São Paulo que os Arquivos Brasileiros de Oftalmologia foi indexado na Pub Med.

Mesmo não sendo oftalmologista, fiquei muito feliz com essa notícia.

Os Arquivos é uma excelente revista e acredito que este fato é decorrente, em grande parte, do seu trabalho como Editor. Parabéns!
No momento, estou fazendo um pós-doutorado em uma unidade do INSERM em Paris (Fisiopatologia das doenças oculares e inovações terapêuticas) e sempre que tenho oportunidade apresento o site dos Arquivos aos pesquisadores daqui.

Um abraço,

\section{Armando da Silva Cunha}

Doutor em Ciências Farmacêuticas pela Universidade de Paris X1.

Professor de Farmacotécnica e Tecnologia Farmacêutica da Faculdade de Farmácia da Universidade Federal de Minas Gerais.

São Paulo, 6 de dezembro de 2004

Prof. Dr. Harley Edison Amaral Bicas

Editor

Arquivos Brasileiros de Oftalmologia

Prezado Harley,

Tomei conhecimento ontem da correspondência enviada pelo Department of Health \& Human Services aos Arquivos Brasileiros de Oftalmologia.

Sua equipe, tão bem liderada por você conseguiu um dos feitos mais importantes da Oftalmologia Brasileira das últimas décadas. O Brasil, finalmente, tem uma revista científica de oftalmologia indexada.

Neste mundo cada vez mais competitivo onde fracos e pequenos não sobrevivem à inclusão, os Arquivos Brasileiros de Oftalmologia estarem indexados entre as melhores revistas oftalmológicas do mundo é prova de maturidade e competência da Oftalmologia Brasileira.

As três gerações anteriores que editaram os Arquivos Brasileiros de Oftalmologia começando pelo meu Avô, passando para o meu Pai e para mim, sonharam em conseguir esse êxito. 
Estamos todos de parabéns e também, institucionalmente, o Conselho Brasileiro de Oftalmologia que soube e tem sabido dar o apoio e estímulos necessários aos Arquivos Brasileiros de Oftalmologia, mantendo-o dentro do ambiente economicamente protegido e politicamente respeitado, evitando intromissão em áreas que são exclusivas da Editoria Científica.

Mais uma vez quero expressar meu orgulho como Oftalmologista ex-editor dos Arquivos Brasileiros de Oftalmologia em ver a Editoria Científica tão bem representada e constituída.

Os desafios continuam e a responsabilidade é cada vez maior.

Agora, temos de continuar a prestigiar os Arquivos Brasileiros de Oftalmologia e exigir de todos nós um nível de artigos que leve a impacto significativo e número grande de citações.

Cordialmente,

\section{Prof. Dr. Rubens Belfort Jr}

Prof. Titular de Oftalmologia - Universidade Federal de São Paulo - UNIFESP Presidente - World Ophthalmology Congress

\section{Belo Horizonte, 14 de dezembro de 2004}

Prof. Harley Amaral Bicas

Editor dos Arquivos Brasileiros de Oftalmologia

O Colegiado do Programa de Pós-Graduação em Oftalmologia da Faculdade de Medicina da Universidade Federal de Minas Gerais deseja parabenizá-lo pelo reconhecimento inter- nacional do elevado nível científico dos Arquivos Brasileiros de Oftalmologia.

Queira por gentileza estender os nossos cumprimentos aos Editores Associados, Conselho Administrativo e Conselho Editorial, bem como aos Editores que o precederam.

Seu trabalho profícuo foi decisivo para esta histórica conquista da Oftalmologia Brasileira.

Atenciosamente,

Prof. Márcio Nehemy

Coordenador do Programa de Pós-Graduação em Oftalmologia da FM/UFMG

Belo Horizonte, 27 de dezembro de 2004.

Prof. Harley Amaral Bicas

Editor dos Arquivos Brasileiros de Oftalmologia

O Prof. Fernando Oréfice vem se associar com o Departamento de Oftalmologia, Otorrinolaringologia e Fonoaudiologia da Faculdade de Medicina da Universidade Federal de Minas Gerais no sentido de parabenizá-lo pela grande conquista obtida por V.Sa. nos Arquivos Brasileiros indexados.

Atenciosamente,

Prof. Joel Edmur Boteon

Chefe do Depto. de Oftalmologia, Otorrinolaringologia e Fonoaudiologia da Faculdade de Medicina da UFMG.

\section{Errata}

Nos Arq Bras Oftalmol. 2004;67(5):749-53, artigo intitulado “Acuidade visual e função de bastonetes em pacientes com retinose pigmentária", a cor correta da legenda da figura 1 (pequeno quadrado na parte inferior do gráfico) é vermelho para Voluntário normal e preto para RP ligada ao X (paciente com retinose pigmentária ligada ao cromossomo X), conforme gráfico abaixo.

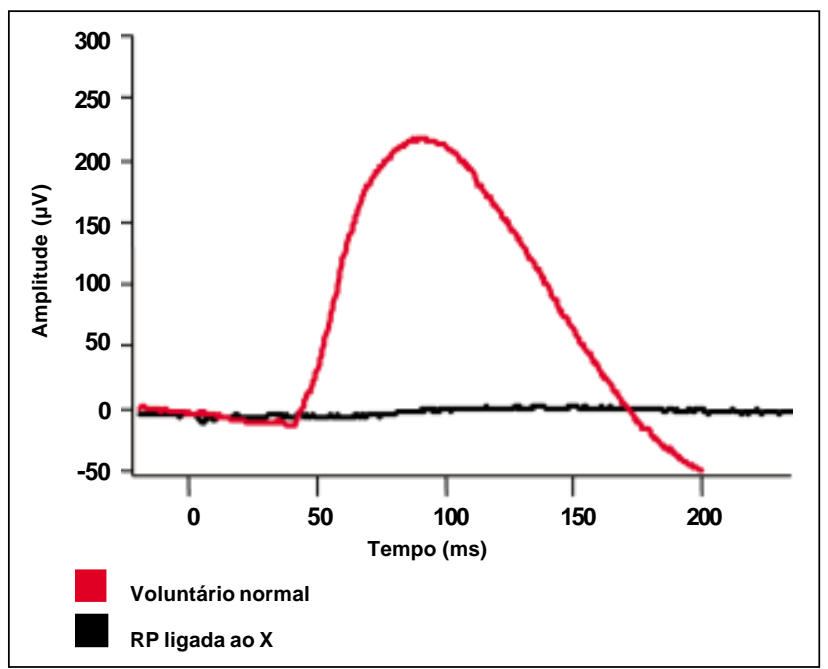

